$\mathbb{T}$ periodica polytechnica

\author{
Transportation Engineering \\ $36 / 1-2(2008) 29-32$ \\ doi: 10.3311/pp.tr.2008-1-2.06 \\ web: http://www.pp.bme.hu/tr \\ (c) Periodica Polytechnica 2008
}

RESEARCH ARTICLE

\section{Minimizing the baggage loss at airports}

\author{
Katalin Emese Bite
}

Received 2007-10-08

\begin{abstract}
Nowadays both airports and airlines are having serious problems related to Baggage Reconciliation. Many transfer baggages are directed to false destinations or simply getting lost during the flight procedures. Some of these however, get taken away by other passengers by mistake (due to similarities in baggages) or intentionally stolen. Irrespectively of whether the loss can be attributed to a human or a computer error, it is causing enormous losses for both the airlines and the airports. To avoid these problems a new technology must be introduced at airports. This technology is Radio Frequency Identification (RFID) that minimizes the false identification of the baggages.
\end{abstract}

\section{Keywords}

Airport · baggages $\cdot$ passengers $\cdot$ lost $\mathcal{E}$ found $\cdot$ RFID
Katalin Emese Bite

Department of Transport Economics, BME, H-1111 Budapest Bertalan L. u. 2., Hungary

e-mail: bitekati@kgazd.bme.hu

\section{Introduction}

Since today more and more business and leisure travelers are flying to their destinations, the airports operate at their peak capacities to be able to satisfy the continuously increasing demand. Most of these people are flying through a third airport (hub airport which is used as the transfer place) before reaching the final destination, as most of the airlines operate in a hub-and-spoke manner. Sometimes the transfer time is very short, so it is just question of luck if someone's luggage is arriving on time (with its owner on board) to the final destination. The transfer time optimally should be at least one hour or more to make sure that the baggage will arrive as well.

Another place to loose a baggage is at the baggage claim of the final airport. After collecting the baggages the passenger is leaving the airport without having been checked if she/he is taking her/his own luggage and not someone else's.

At some American or at the Hanoi Airport in Vietnam, dedicated service people are checking the bag tag's manually right before travelers leave the customs area. This, however, is done only at a few places, and where it is, the whole checking process is painfully slow. A barcode reader is helpful but does not speed up the process considerably.

\section{Today's applied Baggage Reconciliation system of the airports}

At the departure hall the passenger is checking-in his baggage, this will be part of the Departure Control System (DCS). The DCS after entering all the necessary data will print a long Baggage Tag (Bag Tag) with a barcode. The barcode is serving the identification until the final destination. The longer part of this Bag Tag gets the checked-in baggage. The passenger is receiving the smaller slip that contains the same barcode as the checked-in baggage. In case of baggage loss the airline is able to identify and find out where the baggage has been lost. Without the passenger having this receipt the airline is not obligated to find the lost luggage and compensate the passenger.

After the Check-in the ways of the passenger and the baggage will separate and unite again at the Baggage Claim of the final destination. The following graph (Fig. 1) shows the way and the 
steps a passenger and a luggage is taking during a travel by an airplane:

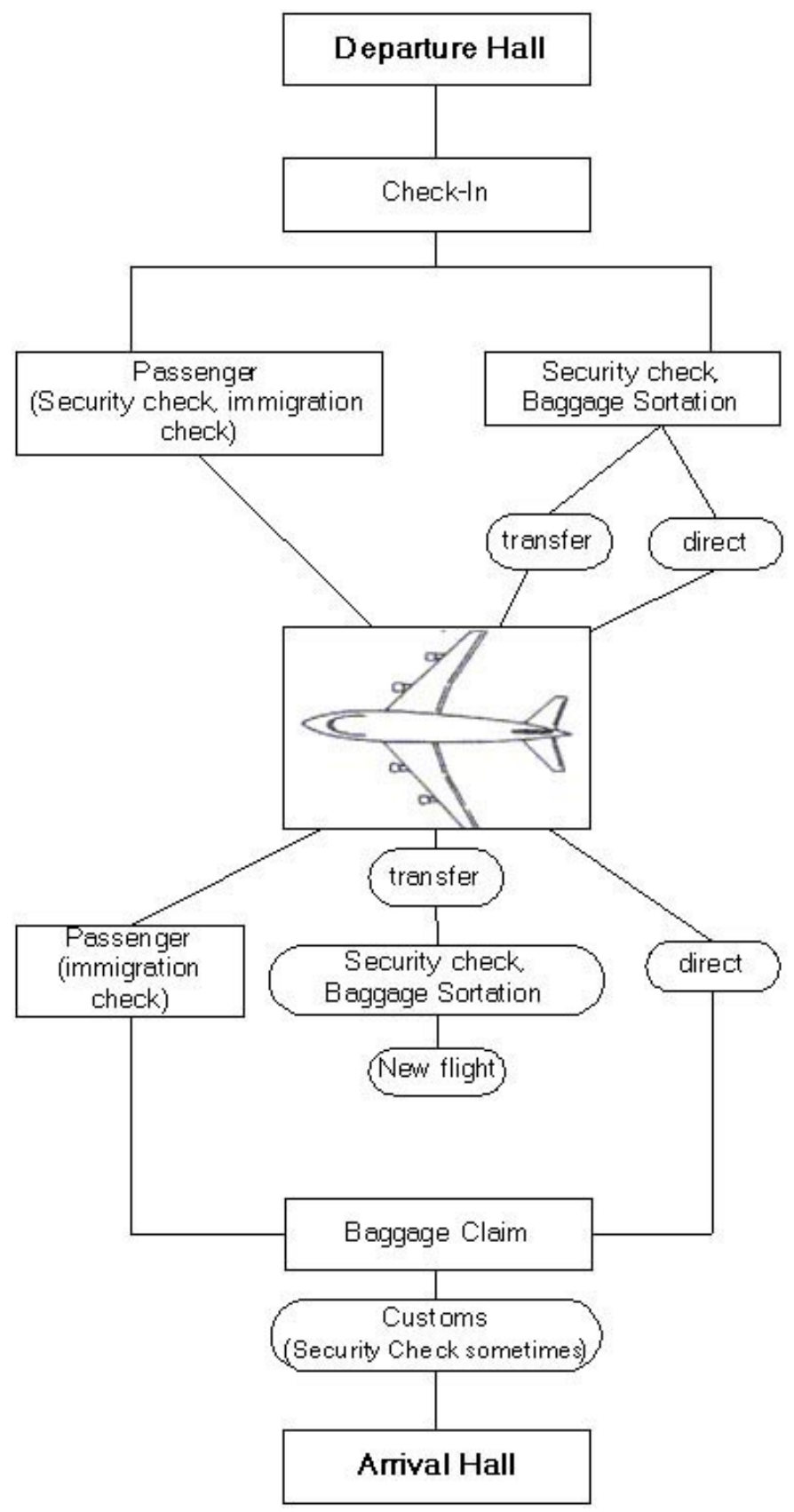

Fig. 1. Passenger and baggage flow during the flight procedure

Most of the baggage loss is the result of either too short transfer time or an error in the reconciliation technology. Today, at the airports, scanner is used as reconciliation technology that translates the encoded barcode and shows the stevedore to which baggage cart or container luggage should be directed to.

If the transfer time is one hour or less, the baggage is tagged with the ShoCon sign. In case, however, when the airplane is delayed and the baggage needs to be transferred quickly to the next airplane there is no special sign tagged on the luggage (originally it supposed to arrive on time and supposed to have enough transfer time), the possibility of the non arrival of the baggage is very high.

In some cases the reason of the lost baggage is that somebody takes a wrong luggage. Nobody is checking if the baggage was taken by its owner or another person.

\subsection{Problems with the nowadays used barcode-scanner system}

Most of the world's airports are using a scanners and a paper printed barcodes for the baggage identification.

The key problems with the barcode and scanner are as follows:

- The barcode needs optical sight, without the line of sight, it can not be read

- Concurrently the scanner is able to read only a single barcode, so it is much more time consuming

- Bar code baggage tag read rates average $85 \%$

- Barcode is printed on a paper that easily crumples, thus the scanner is not able to decode the information properly

- After printing the barcode it is not possible to overwrite the information (only by printing a new one)

- The paper of the barcode is quite long, full of information that comes off easily, thus making it impossible to the stevedore is unable to identify where the luggage is supposed to be sent and the airline is unable to find it in the computer database. It will be regarded as the airline mistake and the airlin's has to compensate the passenger.

- Fig. 2 shows that the paper of the barcode printed on a longhanging paper only attached at the middle to the luggage. The most important part of the paper is just hanging down - without being fixed to the luggage- so it can easily come off or someone can tear it away.

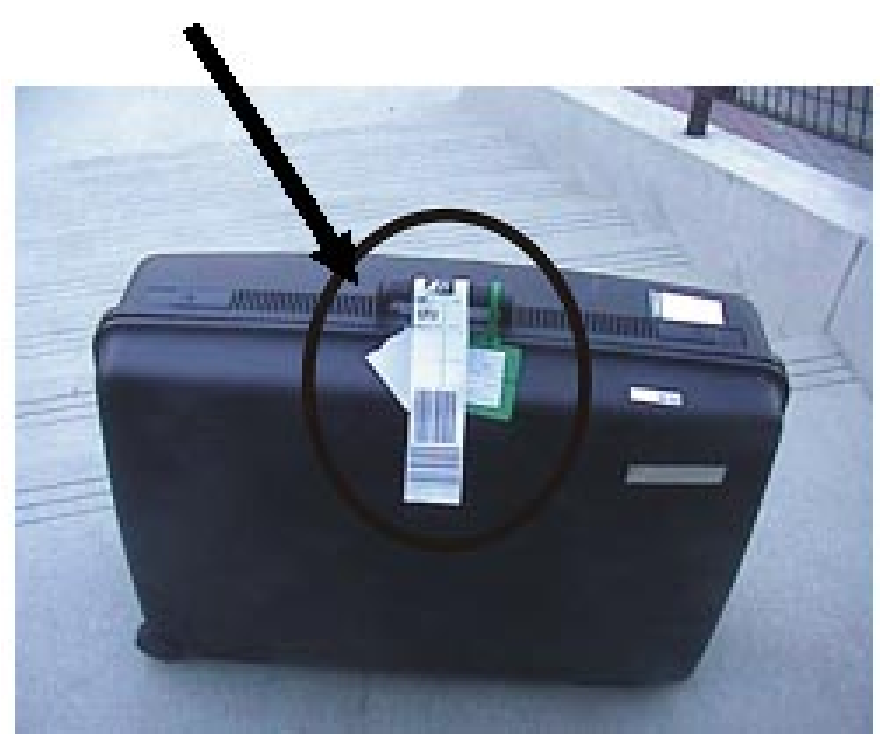

Fig. 2. Today's Baggage barcode solution 


\section{Radio Frequency Identification as the new technol- ogy}

Radio Frequency Identification (RFID) is a technology incorporated into a silicon chip that emits a radio signal which matches a user-defined serial number with an item. In this case the item is a piece of check-in baggage. This number can be read at a distance by an antenna. The following characteristics enable baggages to be sorted automatically and loaded faster than with barcode systems while reducing the number of mishandled baggages and its associated costs at the same time.

The main differences between the RFID and the barcodescanner technology are listed below:

- The tag is read by an antenna, it does not need optical sight

- Greater amount of baggages can be read simultaneously

- It is able to talk-write to a single tag allowing updating the status of the baggage as it is processed

- Barcode baggage tag read rates average $85 \%$ while RFID baggage read rates range between $95-99 \%$.

\subsection{International approach to RFID for airports}

At the Passenger Services Conference in Geneva November 2005 the International Air Transport Association (IATA) has introduced a global standard for RFID baggage tags that paves the way for the use of RFID. In 2005, however, only two or three European countries have permitted site licenses for testing at the higher power level.

Various tests are conducted at major airports with RFID baggage tags. Some of these airports include Las Vegas McCarran International Airport, Hong Kong, Atlanta, Denver, Los Angeles, Narita Japan and some Korean airports.

For 2004 Delta Airlines has tagged its 40 thousand passengers' baggage within a pilot program.

While in 2004, the amount of RFID enabled baggage tags delivered was only a couple of thousands (and all in a trial setting), by 2005 , however, this amount has increased to about 15 million with an average price of 22 cents.

These airports testing the RFID are putting the RFID tag into a paper and then attaching the paper to the baggage. Although the paper can come off, but the identification is much easier.

IATA calculates that airlines would save $\$ 768$ million annually from reducing only $1 \%$ of their mishandled baggages. Even more can be saved by airports, about three times so much.

\subsection{Using RFID tag not only for baggages and not with pa- per combined}

The airports testing RFID are only using the RFID tag as a baggage tag to minimize the costs for the lost baggages. It is necessary to profit more from this new technology and apply it for the baggages as for the passengers too. The passenger's way after the check-in could be tracked until the end of the flight procedure. This would make the followings possible:
- If the passenger is having an RFID tag with the same data as her/his baggage, the passenger-baggage check at the customs - before leaving the airport - could be effectively completed. The possibility that a baggage gets taken away by another passenger by accident or intentionally stolen would be almost impossible. It is not manually checked, so it would be quick and it wouldn't influence or slow down the passenger flow.

- With the technology becoming ubiquitous in the future, the RFID tag could be built into a paper, watch, bracelet, etc. If the RFID tag would be implemented into a bracelet it could be machined fixed to the baggage. (It would be almost impossible to remove the bracelet from the baggage.) The possibility that the Bag Tag comes off or someone tears it away is zero. The machine that fixes the bracelet to the baggage could be built into the check-in counter. An example is shown in the Fig. 3.

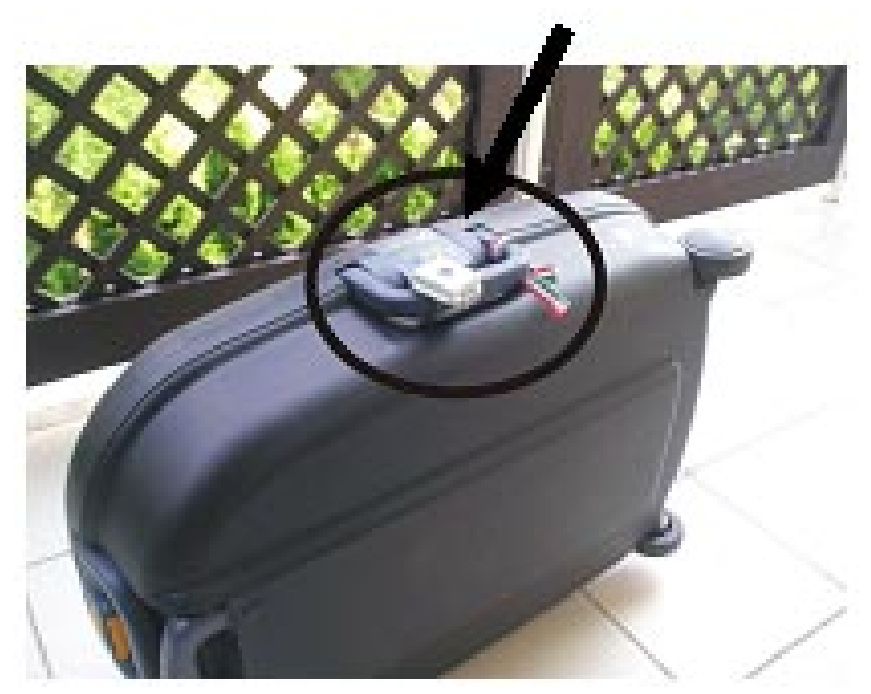

Fig. 3. . RFID implemented into a bracelet

- This bracelet would have a small monitor to show the passenger the actual data needed. This could include after the check-in the flight information, and at the arrival at the final destination the details about the baggage claim. It makes the passenger's orientation much easier.

- With the bracelet having a sound source it would be possible to warn the passenger to be on time to the flight and not to be late. Or if the passenger is late to the flight it simplifies to find the passenger. The flight coordinator can contact the passenger or simply to find him/her. This is still faster than removing the passenger's baggage from the baggage compartment of the plane.

Airports and not airlines should be the owners of the new technology and issue the baggage tags in future. If only the airline were the owner it would only use it for its own baggage flow. Different airlines are applying different systems, and the main importance is the link between the airports and the standardization in this technology. It complicates system if each 
airline signs a contract of cooperation. If each airline applies its own it results a very complicated baggage sortation that is much more time-and-space consuming. Today the baggage tagging is according to the flight at the check-in. The airlines operating a code-share flight are using the same DCS and technology. If an airline that applies the RFID bracelet tagging, is operating a code-share flight with one or more airlines that do not apply the RFID bracelet (or RFID implemented into a paper), it would increase the agreements (costs) between the airlines. The implantation costs and the chip prices are too high for the airlines. The airlines are using only a part of the airport and not the whole airport; this technology could be applied for the many airport operations. And it is unnecessary that each airline develops and implements its own technology. It is much more efficient, less complicated and cheaper if the airport is the developing and implementing the applied technology and the airline is renting it. Most efficient is to work out a strategy for the RFID bracelet for all the world's airports and the airports are given a time period to implement the whole technology.

\section{Conclusion}

Major airlines have every year a high number of issues to be solved related to loosing baggages on the way from one part of the world to the other one. In summer 2007 at the $13^{\text {th }}$ International Congress on Sound and Vibration (ICSV) in Cairns, Australia some of the exhibitors' exhibits had not arrived on time because of being wrongly identified and sent to an incorrect destination.

The costs generated by baggage loss are very high for both the airlines and the airports. The application of RFID technology would reduce these costs extremely. Today's implementation and chip prices are very high but with the time they will decrease. The average industry cost per mishandled baggage is US\$100. Approximately $1 \%$ of the 1.7 billion bags that passes through the system every per year is mishandled and RFID is an ideal candidate to reduce these loss. Upon full implementation, RFID would save the industry US\$760 million annually.

\section{References}

1 RFID for Airports and Airlines 2007-2017, IDTechEx, March 2007.

2 available at http://www.researchandmarkets.com/reports/c30823

3 Bite KE, Safety Baggage Reconciliation System planning at airports, Budapest, 2005. MSc. Thesis.

4 Beliczay T, A radiofrekvenciás azonosítás (RFID) központi eleme: a bélyeg, Transpack (December 2005), 24-26.

5 IATA Simplifying the business, Geneva, 2004 Oct.

6 Passenger Services Conference Resolutions Manual, 106 2004. 24th Edition.

7 IATA Passenger Services Conference, Geneva, 2005 Nov. 